\title{
Blood parameters in fattening pigs fed whole-ear corn silage and housed in group pens or in metabolic cages ${ }^{1}$
}

\author{
F. Abeni, $* 2$ F. Petrera,* A. Dal Prà,* L. Rapetti, $\uparrow$ L. Malagutti, $\uparrow$ and G. Galassi $\uparrow$ \\ *Consiglio per la ricerca in agricoltura e l'analisi dell'economia agraria (CRA), Centro di ricerca per le produzioni \\ foraggere e lattiero-casearie-Sede distaccata di Cremona, Via Porcellasco 7, 26100 Cremona, Italy; and †Università \\ degli Studi di Milano, Dipartimento di Scienze Agrarie e Ambientali, Via Giovanni Celoria 2, 20133 Milano, Italy
}

\begin{abstract}
The aim of this work was to evaluate the effects of the inclusion of whole-ear corn silage (WECS) in diets for advanced fattening heavy pigs (substitution for part of the dry corn and wheat bran) allocated or not in metabolic cages on the main blood parameters. The high-moisture shelled corn is largely used in pig feeding while WECS is less often used despite the fact that it increases the DM crop yield. Three experimental diets were fed to 27 barrows (Italian Large White $\times$ Italian Duroc), with an average BW of $98.2( \pm 5.6) \mathrm{kg}$ at the start of the trial, and randomly allotted to 3 experimental groups including a control diet $(\mathrm{CON})$ containing cereal meals (corn, barley, and wheat, $80.2 \%$ DM in total), soybean meal ( $9 \%$ $\mathrm{DM})$, wheat bran ( $8 \% \mathrm{DM})$, minerals and supplements (2.8\% DM), and 2 diets containing WECS (15 or $30 \%$ DM referred to as $15 \mathrm{WECS}$ and $30 \mathrm{WECS}$, respectively) in partial or complete substitution for wheat bran and corn meal. The pigs were randomly housed in 9 pens with 3 animals per pen and 3 pens per dietary treatment. Six pigs per each of the 3 treatments were moved from the pens to individual metabolic cages for 3 consecutive periods ( 2 pigs per treatment per period). Each
\end{abstract}

period lasted $14 \mathrm{~d}$, and blood was collected at the start and at the end of the periods. Blood was drawn from the jugular vein before feed distribution in the morning, at $14 \mathrm{~d}$ intervals, and analyzed for hematological, metabolic, and serum protein profiles. The effect of the metabolic cage housing was included in the statistical model to compare the results obtained in the 2 different environments of restrained and group-housed barrows. The WECS affected the neutrophil to lymphocyte ratio and mean corpuscular hemoglobin concentration. The main diet effect on plasma metabolites was recorded for plasma NEFA, with higher values in WECS diets compared with the CON. The metabolic cage housing affected both hematological (red blood cell count, hemoglobin, hematocrit) and metabolic (protein and its fractions) items, which can be markers of hemodilution. These results indicate the possibility to use this feed in the diet of heavy pigs without negative effects on physiology. The absolute values from metabolic profile of pigs in metabolic cages must be considered with caution for possible comparisons with values obtained on-field in group pens, particularly because a different hemodilution may affect the results.

Key words: corn silage, hematology, metabolic cage, metabolic profile, pigs

(C) 2015 American Society of Animal Science. All rights reserved.

J. Anim. Sci. 2015.93:3901-3908 doi:10.2527/jas2015-9126

\section{INTRODUCTION}

Increases in corn grain prices and grain-drying cost have stimulated interest in silage corn products in pig feeding (Bucholtz, 2012). High-moisture shelled corn is largely used in pig feeding as an al-

\footnotetext{
${ }^{1}$ Supported by Progetto AGER (Grant Number 2011-0280).

${ }^{2}$ Corresponding author: fabiopalmiro.abeni@entecra.it

Received March 21, 2015.

Accepted May 17, 2015.
}

ternative feed to dry corn, while whole-ear corn silage (WECS) is used less often probably because it is considered too high in fiber despite the fact that it might increase the DM crop yield by 15 to $20 \%$.

The introduction of WECS in diets for growing and finishing pigs requires the assessment of possible effects on blood features that may result from diet-related stress due to the physical form or particle size of the feed, which can determine welfare problems like gastric ulcers (Cappai et al., 2013; Mason et al., 2013). At the same time, a possible reduction in mineral availability 
in the growing phase must be considered and monitored, namely because of changes in phosphorous availability compared to that of diets including wheat bran (Boyd et al., 1983; Gutzwiller et al., 2011). However, data on barrow hematological and metabolic profiles are scarce, old (Miller et al., 1961b; Odink et al., 1990), or from a productive system very different from that adopted in typical ham production (Klem et al., 2010). Additionally, data obtained from the digestion trial (metabolic cage) are not generally compared with those from the same diet fed in group pens (the real productive condition). The metabolic cage also provides welfare information that may affect, apart from moral concerns and legislative obligations (Schrøder-Petersen and Simonsen 2001), a possible bias in the results obtained.

The present research aimed to evaluate the effects of partial substitution of dry corn and wheat bran with WECS in the diet of heavy pigs on their metabolic and hematological profile. To evaluate if containment in a metabolic cage has an effect on the blood profiles of animals besides the stress status, we compared the barrows in the metabolic cage with their counterpart in the barn-pens.

\section{MATERIALS AND METHODS}

\section{Animals and Diets}

All animals were cared for in accordance with the guidelines on animal welfare in Animal Research of the Italian Legislative Decree Number 116/1992 (Italian Ministry of Health, 1992). The study was performed at the Cascina Baciocca experimental farm of the Università degli Studi di Milano, located in Cornaredo, Italy.

Three experimental diets were fed to 27 barrows (Italian Large White $\times$ Italian Duroc). The animals, with an average BW of $98.2( \pm 5.6) \mathrm{kg}$, were randomly housed in 9 pens with 3 animals per pen and 3 pens per treatment. As reported in our previous companion paper (Zanfi et al., 2014), to determine diet digestibility, 2 pigs per each of the 3 dietary treatments were moved from the pens to individual metabolic cages for 3 consecutive periods. Each period lasted $14 \mathrm{~d}$, and blood was collected at the start (before the transfer from pens to metabolic cages) and at the end (before the transfer from metabolic cages to pens) of the periods. Consequently, 6 animals per each of the 3 dietary treatments were tested. Blood was also collected from the 9 animals remaining in the barn-pens throughout the whole trial.

The experimental diets (Table 1) included a control diet (CON) containing cereal meals (corn, barley, and wheat, $80.2 \%$ of DM in total), soy bean meal $(9 \%$ of DM), wheat bran ( $8 \%$ of DM), minerals and supplements $(2.8 \%$ of DM), and 2 diets containing WECS at
Table 1. Composition and analysis of the experimental diets

\begin{tabular}{lccc}
\hline \hline Diet $^{1}$ & CON & 15WECS & 30WECS \\
\hline Ingredient, \% DM & & & \\
Corn meal & 47.1 & 36.1 & 25.1 \\
Barley meal & 23.1 & 23.1 & 23.1 \\
Wheat meal & 10.0 & 10.0 & 10.0 \\
Soya bean meal, extracted & 9.0 & 9.0 & 9.0 \\
Wheat bran & 8.0 & 4.0 & 0.0 \\
Whole ear corn silage & 0.0 & 15.0 & 30.0 \\
NaCl & 0.36 & 0.36 & 0.36 \\
CaCO & 1.13 & 1.13 & 1.13 \\
CaHPO & 0.75 & 0.75 & 0.75 \\
L-lys HCL & 0.09 & 0.09 & 0.09 \\
Supplement ${ }^{2}$ & 0.47 & 0.47 & 0.47 \\
DM, \% & 91.5 & 86.5 & 81.8 \\
CP, \% DM & 14.0 & 13.7 & 13.6 \\
NDF, \% DM & 15.8 & 15.4 & 15.2 \\
ADF, \% DM & 4.9 & 5.2 & 5.5 \\
Ether extract, \% DM & 2.7 & 2.7 & 2.6 \\
Ash, \% DM & 5.5 & 4.8 & 4.5 \\
Starch \% DM & 47.5 & 48.3 & 49.1 \\
\hline
\end{tabular}

${ }^{1} \mathrm{CON}$, control diet with $0 \%$ whole-ear corn silage; $15 \mathrm{WECS}$, diet with $15 \%$ whole-ear corn silage of DM; $30 \mathrm{WECS}$, diet with $30 \%$ whole-ear corn silage of DM.

${ }^{2}$ Supplied per kilogram DM of complete diet: vitamin A, 9400 IU; vitamin $\mathrm{D}_{3}, 1880 \mathrm{IU}$; vitamin $\mathrm{E}, 47 \mathrm{mg}$; vitamin $\mathrm{K}_{3}, 1.0 \mathrm{mg}$; thiamine, $0.9 \mathrm{mg}$; riboflavin, $4.7 \mathrm{mg}$; niacin, $23.5 \mathrm{mg}$; vitamin $\mathrm{B}_{6}, 0.9 \mathrm{mg}$; vitamin $\mathrm{B}_{12}, 0.024 \mathrm{mg}$; pantothenic acid, $12 \mathrm{mg}$; biotin, $0.19 \mathrm{mg}$; choline chloride, $118 \mathrm{mg}$; Fe, 126 $\mathrm{mg}$ from $\mathrm{FeSO}_{4} \cdot \mathrm{H}_{2} \mathrm{O} ; \mathrm{Cu}, 21 \mathrm{mg}$ from $\mathrm{CuSO}_{4} \times 5 \mathrm{H}_{2} \mathrm{O} ; \mathrm{Zn}, 127 \mathrm{mg}$ from $\mathrm{ZnO}$; $\mathrm{Mn}, 42 \mathrm{mg}$ from $\mathrm{MnO}_{2} ; \mathrm{I}, 0.7 \mathrm{mg}$ from $\mathrm{Ca}\left(\mathrm{IO}_{3}\right)_{2} ; \mathrm{Co}, 0.2 \mathrm{mg}$ from $2 \mathrm{CoCO}_{3}$ $3 \mathrm{Co}(\mathrm{OH})_{2} \times \mathrm{H}_{2} \mathrm{O} ; \mathrm{Se}, 0.2 \mathrm{mg}$ from $\mathrm{Na}_{2} \mathrm{SeO}_{3}$ (pig supplement $0.5 \%$ ).

15 (15WECS) or 30\% (30WECS) on a DM basis to substitute wheat bran and corn meal.

As reported in a companion paper (Zanfi et al., 2014), the particle size measured by the Penn State Particle Separator (Nasco, Fort Atkinson, WI) showed that about $73 \%$ of WECS was retained by the $2-\mathrm{mm}$ sieve, $14 \%$ was collected at the bottom, and $12 \%$ was retained by the $8-\mathrm{mm}$ sieve. A fraction of about $1 \%$ was collected by the $19-\mathrm{mm}$ sieve.

Pigs were fed at 0800 and at $1700 \mathrm{~h}$ and had free access to water. Feed was restricted to allow a daily DMI of $7.2 \% \mathrm{BW}^{0.75}$. At the end of the trial, the animals weighed on average $128.5( \pm 8.6) \mathrm{kg}$.

\section{Clinical, Hematological, and Biochemical Parameters}

Blood was drawn from the jugular vein at 14-d intervals before feeding in the morning. Blood samples for the analysis of the hematological profile were drawn in $\mathrm{K}_{3}$ EDTA-treated tubes $(5 \mathrm{~mL}$, Venoject; Terumo, Leuven, Belgium) and immediately analyzed using a Cell-Dyn 3700 Hematology Analyzer (Abbott Diagnostici, Roma, Italy). The results from the instru- 
ment were monitored with a whole-blood reference control (Cell-Dyn Control). The measurements included total red blood cells (RBC; M/ $\mu \mathrm{L})$, hemoglobin (Hgb; g/dL), hematocrit (HCT; \%), mean corpuscular volume (MCV; fL), mean corpuscular Hgb (MCH; pg), mean corpuscular $\mathrm{Hgb}$ concentration (MCHC; g/dL), width of RBC volume distribution (RDW; \%), total white blood cells (WBC; $\mathrm{k} / \mu \mathrm{L})$, neutrophils (NEU; $\mathrm{k} /$ $\mu \mathrm{L}$ and percentage of WBC), lymphocytes (LYM; $\mathrm{k} / \mu \mathrm{L}$ and percentage of $\mathrm{WBC}$ ), monocytes (MON; $\mathrm{k} / \mu \mathrm{L}$ and percentage of WBC), eosinophils (EOS; $\mathrm{k} / \mu \mathrm{L}$ and percentage of WBC), basophils (BAS; $\mathrm{k} / \mu \mathrm{L}$ and percentage of WBC), total platelet number (PLT; k $/ \mu \mathrm{L})$, mean platelet volume (MPV; fL), and plateletcrit (PCT, \%).

Blood samples for plasma protein profiles were drawn in tubes without anticoagulant, allowed to separate serum, and successively frozen at $-20^{\circ} \mathrm{C}$ until analysis. This analysis was performed with the aim to describe and compare, by a single screening test, the effect of the experimental diet or the effect of the housing environment on the protein synthesis, paying particular attention to the $\gamma$-globulins as a marker of immune function activities. The serum protein profiles were assessed by agarose gel electrophoresis using a standard kit for blood serum proteins (Hydragel 30; Sebia Italia, Firenze, Italy) on an automated multiparametric agarose gel electrophoresis system (Hydrasis; Sebia Italia). The gels were analyzed by a densitometer and dedicated software (Phoresis; Sebia Italia). The obtained fractions were albumin: $\alpha, \beta$, and $\gamma$ globulins.

Blood samples for biochemical metabolic profiles were drawn in lithium-heparin tubes $(10 \mathrm{~mL}$, Venoject; Terumo), immediately centrifuged for plasma separation, and frozen at $-20^{\circ} \mathrm{C}$ until analyzed. Plasma glucose, total cholesterol, triglycerides, total bilirubin, urea, creatinine, albumin, total protein, $\mathrm{Ca}$, inorganic $\mathrm{P}, \mathrm{Mg}, \mathrm{Na}$, $\mathrm{K}, \mathrm{Cl}$, and $\mathrm{Fe}$ contents were determined using an automated analyzer for biochemical chemistry (ILAB Aries; Instrumentation Laboratory, Lexington, MA) working at $37^{\circ} \mathrm{C}$ by colorimetric and enzymatic methods using commercial kits (Instrumentation Laboratory). The concentration of NEFA was measured using a commercial kit (NEFA-HR(2); Wako Chemicals GmbH, Neuss, Germany) and D-3-hydroxybutyrate (BHBA) using Randox Chemicals kits (Randox Laboratories Ltd., County Antrim, United Kingdom), adapting them to the analyzer conditions. The selection of markers to assess hepatic condition (in terms of possible injuries) was conducted following the suggestions of Boone et al. (2005). Alanine aminotransferase (ALT, EC 2.6.1.2) and aspartate aminotransferase (AST, EC 2.6.1.1) were used to assess hepatocellular injury. Alkaline phosphatase (ALP, EC 3.1.3.1) was considered both for its possible involvement in the description of hepatobiliary injury and for its possible role as a marker of osteoblast activity. Total bilirubin and $\gamma$-glutamyltransferase (GGT, EC 2.3.2.2) were used as indices of hepatobiliary injury. L-lactate dehydrogenase (LDH, EC 1.1.1.27) was considered as a marker of muscular tissue damage, and tartrate-resistant acid-phosphatase (TRAP) was an indirect marker of bone mobilization. These enzymatic activities, including plasma amylase (EC 3.2.1.1) were assessed using commercial kits supplied by the same producer of the automated analyzer for biochemical chemistry (ILAB ARIES; Instrumentation Laboratory). Plasma cation-anion balance (CAB) was calculated for each blood sample according to the following formula: $\mathrm{CAB}(\mathrm{mEq} / \mathrm{L})=\mathrm{Na}$ $(\mathrm{mEq} / \mathrm{L})+\mathrm{K}(\mathrm{mEq} / \mathrm{L})-\mathrm{Cl}(\mathrm{mEq} / \mathrm{L})$.

\section{Statistical Analysis}

The results were analyzed using the MIXED procedure of SAS (SAS Inst. Inc., Cary, NC) according to Littell et al. (1998). Data were tested for normal distribution using the Shapiro-Wilk test. Variables not normally distributed were subjected to $\log _{10}$ transformation to obtain a normal distribution of values before statistical analysis (Farver, 1997).

The effect of diet (CON, 15WECS, and 30WECS), time of sampling (3 repeated samples, equally distanced by $2 \mathrm{wk}$ ), exit from the metabolic cage (no or yes, 2 levels), and interactions were included in the statistical model. The random variable was pig within diet. Each variable analyzed was subjected to 5 covariance structures: simple (SIMPLE), compound symmetry (CS), autoregressive of first order (AR1), ante-dependence of first order (ANTE1), and unstructured (UN). Using Akaike's information criterion, the best fitting structure was chosen. Interactions were removed from the model when not significant. Effects were considered significant when $P<0.05$; a trend was considered when $P<0.10$. Simple Pearson correlations were calculated among variables for the entire period using the CORR procedure of SAS and reported when $P<0.01$.

\section{RESULTS}

\section{Hematological Profile}

Results from different WECS percentages in the diet and the effect of the exit from a metabolic cage are summarized in Table 2. Mean corpuscular hemoglobin concentration and the NEU to LYM ratio were affected by $\operatorname{diet}(P<0.05)$. All the other considered items were not affected by $\operatorname{diet}(P>0.05)$; a trend was recorded for NEU counts $(P=0.060)$, EOS count $(P=0.071)$, and PLT $(P=$ 0.086). Total WBC, NEU, MON, BAS, RBC, Hgb, HCT, $\mathrm{MCV}$, and $\mathrm{MCHC}$ were affected by sampling date, and 
Table 2. Effects of different dietary inclusion of whole-ear corn silage (WECS) and the exit from a metabolic cage on hematological profile in barrows; values are reported as LSM

\begin{tabular}{|c|c|c|c|c|c|c|c|c|c|c|}
\hline \multirow[b]{2}{*}{ Item } & \multicolumn{3}{|c|}{$\operatorname{Diet}^{1}$} & \multicolumn{2}{|c|}{ Housing } & \multirow[b]{2}{*}{ SEM or $\mathrm{CI}^{2}$} & \multicolumn{4}{|c|}{$P$-value } \\
\hline & $\mathrm{CON}$ & 15WECS & 30WECS & Pen & Cage & & Diet (D) & Sampling (S) & $\mathrm{D} \times \mathrm{S}$ & Housing \\
\hline $\mathrm{WBC}^{3}, \mathrm{k} / \mathrm{mL}$ & 16.1 & 16.0 & 17.9 & 16.8 & 16.5 & $16.0-17.4$ & 0.275 & 0.002 & 0.003 & 0.493 \\
\hline $\mathrm{NEU}, \mathrm{k} / \mathrm{mL}$ & 3.45 & 4.41 & 4.75 & 4.25 & 4.09 & $3.89-4.55$ & 0.060 & 0.002 & 0.398 & 0.511 \\
\hline $\mathrm{LYM}, \mathrm{k} / \mathrm{mL}$ & 10.5 & 9.4 & 11.1 & 10.3 & 10.2 & $9.8-10.7$ & 0.106 & 0.587 & 0.128 & 0.864 \\
\hline NEU to LYM, ratio & 0.33 & 0.47 & 0.43 & 0.42 & 0.39 & $0.38-0.45$ & 0.020 & 0.343 & 0.592 & 0.458 \\
\hline $\mathrm{MON}, \mathrm{k} / \mathrm{mL}$ & 1.06 & 1.11 & 1.07 & 1.11 & 1.05 & $1.01-1.18$ & 0.921 & 0.053 & 0.760 & 0.356 \\
\hline $\mathrm{EOS}, \mathrm{k} / \mathrm{mL}$ & 0.57 & 0.38 & 0.49 & 0.51 & 0.44 & $0.44-0.54$ & 0.071 & 0.220 & 0.098 & 0.062 \\
\hline $\mathrm{BAS}, \mathrm{k} / \mathrm{mL}$ & 0.22 & 0.31 & 0.21 & 0.24 & 0.25 & $0.22-0.27$ & 0.144 & 0.003 & 0.515 & 0.830 \\
\hline $\mathrm{RBC}, \mathrm{M} / \mathrm{mL}$ & 6.88 & 6.84 & 7.05 & 6.55 & 7.29 & 0.07 & 0.456 & $<0.001$ & 0.987 & $<0.001$ \\
\hline $\mathrm{Hgb}, \mathrm{g} / \mathrm{dL}$ & 13.4 & 13.2 & 13.6 & 12.7 & 14.2 & 0.13 & 0.519 & 0.001 & 0.994 & $<0.001$ \\
\hline HCT, \% & 39.8 & 38.8 & 40.5 & 37.5 & 41.9 & 0.41 & 0.211 & $<0.001$ & 0.948 & $<0.001$ \\
\hline $\mathrm{MCV}, \mathrm{fL}$ & 58.0 & 56.8 & 57.6 & 57.3 & 57.6 & 0.50 & 0.621 & $<0.001$ & 0.019 & 0.065 \\
\hline $\mathrm{MCH}, \mathrm{pg}$ & 19.6 & 19.4 & 19.3 & 19.4 & 19.4 & 0.18 & 0.771 & 0.108 & 0.051 & 0.796 \\
\hline $\mathrm{MCHC}, \mathrm{g} / \mathrm{dL}$ & 33.8 & 34.1 & 33.6 & 33.8 & 33.8 & 0.09 & 0.041 & 0.005 & 0.025 & 0.982 \\
\hline RDW, \% & 21.8 & 21.8 & 22.0 & 21.6 & 22.1 & 0.23 & 0.951 & 0.121 & 0.518 & 0.101 \\
\hline PLT, k/mL & 295 & 360 & 286 & 340 & 288 & 15.0 & 0.086 & 0.422 & 0.109 & 0.011 \\
\hline MPV, fL & 11.5 & 11.2 & 12.3 & 12.2 & 11.1 & 0.34 & 0.416 & 0.131 & 0.001 & 0.008 \\
\hline PCT, $\%$ & 0.34 & 0.42 & 0.36 & 0.40 & 0.34 & 0.02 & 0.220 & 0.306 & 0.051 & 0.027 \\
\hline
\end{tabular}

${ }^{1} \mathrm{CON}$, control diet with $0 \%$ WECS; $15 \mathrm{WECS}$, diet with $15 \%$ WECS on a DM basis; $30 \mathrm{WECS}$, diet with $30 \%$ WECS on a DM basis.

${ }^{2}$ The SEM is pooled and the CI applies to variables not normally distributed.

${ }^{3}$ WBC, total white blood cells; NEU, neutrophils; LYM, lymphocytes; MON, monocytes; EOS, eosinophils; BAS, basophils; RBC, total red blood cells; Hgb, hemoglobin; HCT, hematocrit; MCV, mean corpuscular volume; MCH, mean corpuscular hemoglobin; MCHC, mean corpuscular hemoglobin concentration; RDW, width of RBC volume distribution; PLT, total platelet number; MPV, mean platelet volume; PCT, plateletcrit.

total WBC, MCV, MCHC, MPV, and PCT were also affected by the interaction between diet and sampling date.

The exit from a metabolic cage did not affect total leukocyte number or their populations, but it did $(P<$ 0.001 ) for RBC, HGB, and HCT, with higher values for pigs after the period in the metabolic cage than for those in the barn. In contrast, PLT, MPV, and PCT were reduced $(P<0.05)$ in pigs after metabolic cages compared with those in the barn.

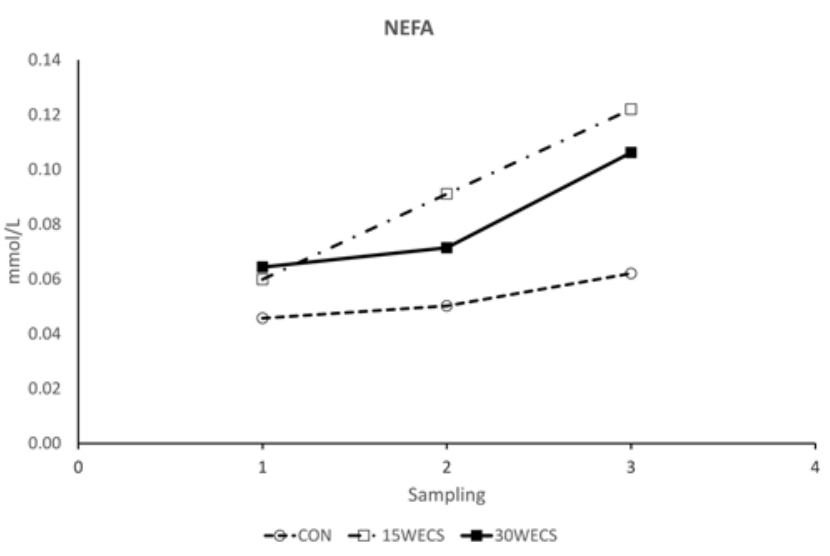

Figure 1. Pattern of plasma NEFA in barrows fed diets with different inclusions of whole-ear corn silage (WECS) including a control diet with $0 \%$ WECS (CON), a diet with $15 \%$ WECS on a DM basis (15WECS), and a diet with $30 \%$ WECS on a DM basis (30WECS). The CI for the general mean is 0.065 to $0.086 \mathrm{mmol} / \mathrm{L}$.

\section{Metabolic Profile}

The energy-related plasma metabolites were unaffected by dietary treatment, except for plasma NEFA $(P=0.051)$, which was also mirrored in the NEFA to total cholesterol ratio $(P=0.046)$ and NEFA to albumin ratio $(P=0.045)$. The diets with the inclusion of WECS evidenced higher values of these items than those in the CON. Time of sampling affected both plasma glucose (decreasing with age) and plasma NEFA concentrations, the latter resulting in increased values with age (Fig. 1).

Among the protein-nitrogen related metabolites, plasma creatinine increased with age (sampling; $P<$ 0.001 ). There was a trend for plasma urea to decrease from CON to an increasing amount of WECS in the diet $(P=0.070)$. Total protein, albumin, and globulins were affected by the exit from a metabolic cage $(P<0.01)$, with higher plasma concentrations recorded in barrows exiting from the cage than those reared in group pens.

Plasma mineral content and enzyme activities related to bone metabolism were unaffected by diet (Table 3). Plasma $\mathrm{Ca}$ and $\mathrm{P}$ were affected by time of sampling and exit from metabolic cage $(P<0.01)$. Plasma ALP activity was affected by time of sampling $(P<0.05)$ and exit from metabolic cage $(P<0.05)$, with lower values than those of pigs in the group pens. L-lactate dehydrogenase was affected by diet $(P=0.005)$. 
Table 3. Effects of different dietary inclusion of whole ear corn silage (WECS) and the exit from a metabolic cage on metabolic profile in barrows; values are reported as LSM

\begin{tabular}{|c|c|c|c|c|c|c|c|c|c|c|}
\hline \multirow[b]{2}{*}{ Item $^{1}$} & \multicolumn{3}{|c|}{$\overline{\text { Diet }^{2}}$} & \multicolumn{2}{|c|}{ Housing } & \multirow[b]{2}{*}{$\mathrm{SEM}$ or $\mathrm{CI}^{3}$} & \multicolumn{4}{|c|}{$\overline{P \text {-value }}$} \\
\hline & $\mathrm{CON}$ & 15WECS & 30WECS & Pen & Cage & & $\operatorname{Diet}(\mathrm{D})$ & Sampling (S) & $\mathrm{D} \times \mathrm{S}$ & Housing \\
\hline Glucose, $\mathrm{mmol} / \mathrm{L}$ & 4.30 & 4.47 & 4.22 & 4.19 & 4.46 & 0.07 & 0.269 & 0.008 & 0.174 & 0.010 \\
\hline Cholesterol, mmol/L & 2.46 & 2.29 & 2.30 & 2.33 & 2.37 & 0.06 & 0.466 & 0.091 & 0.082 & 0.233 \\
\hline Triglycerides, $\mathrm{mmol} / \mathrm{L}$ & 0.29 & 0.29 & 0.24 & 0.28 & 0.27 & 0.02 & 0.360 & 0.094 & 0.411 & 0.635 \\
\hline $\mathrm{NEFA}, \mathrm{mmol} / \mathrm{L}$ & $0.052^{b}$ & $0.087^{\mathrm{a}}$ & $0.079^{\mathrm{a}}$ & 0.078 & 0.065 & $0.065-0.086$ & 0.050 & $<0.001$ & 0.243 & 0.056 \\
\hline Glucose to NEFA, ratio & 78.8 & 62.9 & 43.5 & 53.9 & 66.6 & $48.7-65.6$ & 0.106 & $<0.001$ & 0.103 & 0.033 \\
\hline NEFA to cholesterol, ratio & 21.6 & 38.4 & 34.0 & 33.9 & 27.3 & $27.9-37.5$ & 0.046 & $<0.001$ & 0.266 & 0.024 \\
\hline NEFA to albumin, ratio & 1.42 & 2.40 & 2.10 & 2.19 & 1.70 & $1.81-2.38$ & 0.045 & $<0.001$ & 0.169 & 0.007 \\
\hline BHBA, mmol/L & 0.049 & 0.049 & 0.041 & 0.045 & 0.048 & 0.007 & 0.843 & 0.150 & 0.121 & 0.847 \\
\hline Urea, mmol/L & 4.44 & 4.41 & 3.94 & 4.24 & 4.29 & 0.10 & 0.079 & 0.081 & 0.517 & 0.744 \\
\hline Creatinine, $\mu \mathrm{mol} / \mathrm{L}$ & 168 & 161 & 169 & 163 & 169 & 3.5 & 0.600 & $<0.001$ & 0.178 & 0.187 \\
\hline Total protein, $\mathrm{g} / \mathrm{L}$ & 73.8 & 73.6 & 72.7 & 71.2 & 75.5 & 0.72 & 0.792 & 0.148 & 0.885 & $<0.001$ \\
\hline Albumin, $g / L$ & 37.2 & 36.6 & 37.2 & 35.8 & 38.2 & 0.48 & 0.812 & 0.568 & 0.865 & $<0.001$ \\
\hline Globulins, g/L & 36.7 & 37.0 & 35.5 & 35.5 & 37.3 & 0.59 & 0.532 & 0.019 & 0.689 & 0.005 \\
\hline Albumin to globulins, ratio & 1.02 & 1.00 & 1.06 & 1.02 & 1.03 & 0.02 & 0.473 & 0.018 & 0.557 & 0.565 \\
\hline $\mathrm{Ca}, \mathrm{mmol} / \mathrm{L}$ & 2.62 & 2.64 & 2.63 & 2.60 & 2.67 & 0.02 & 0.922 & $<0.001$ & 0.333 & 0.002 \\
\hline $\mathrm{P}, \mathrm{mmol} / \mathrm{L}$ & 2.60 & 2.58 & 2.64 & 2.67 & 2.55 & 0.02 & 0.453 & 0.003 & 0.814 & 0.005 \\
\hline $\mathrm{Mg}, \mathrm{mmol} / \mathrm{L}$ & 0.80 & 0.78 & 0.81 & 0.79 & 0.81 & 0.01 & 0.436 & 0.316 & 0.818 & 0.350 \\
\hline $\mathrm{Na}, \mathrm{mmol} / \mathrm{L}$ & 144 & 146 & 144 & 144 & 146 & 0.38 & 0.164 & 0.305 & 0.655 & 0.002 \\
\hline $\mathrm{K}, \mathrm{mmol} / \mathrm{L}$ & 5.14 & 4.97 & 5.14 & 5.05 & 5.12 & 0.05 & 0.204 & 0.456 & 0.835 & 0.416 \\
\hline $\mathrm{Cl}, \mathrm{mmol} / \mathrm{L}$ & 103 & 102 & 101 & 102 & 102 & 0.29 & 0.149 & 0.820 & 0.093 & 0.240 \\
\hline $\mathrm{Fe}, \mu \mathrm{mol} / \mathrm{L}$ & 24.8 & 24.0 & 21.6 & 20.7 & 26.2 & 0.59 & 0.074 & 0.211 & 0.161 & $<0.001$ \\
\hline Ca to $P$, ratio & 1.01 & 1.03 & 1.00 & 0.98 & 1.05 & 0.01 & 0.529 & 0.100 & 0.508 & $<0.001$ \\
\hline $\mathrm{CAB}, \mathrm{mEq} / \mathrm{L}$ & 46.9 & 48.4 & 48.1 & 46.9 & 48.7 & 0.30 & 0.105 & 0.441 & 0.912 & $<0.001$ \\
\hline Amylase, U/L & 1896 & 2152 & 1805 & 1915 & 1987 & 103 & 0.370 & 0.013 & 0.782 & 0.071 \\
\hline ALT, U/L & 47.1 & 44.3 & 46.3 & 44.8 & 47.0 & 1.34 & 0.671 & 0.019 & 0.786 & 0.210 \\
\hline $\mathrm{AST}, \mathrm{U} / \mathrm{L}$ & 38.2 & 34.9 & 43.4 & 40.0 & 37.6 & 1.94 & 0.177 & 0.740 & 0.583 & 0.578 \\
\hline GGT, U/L & 39.6 & 34.1 & 37.5 & 37.5 & 36.6 & 1.79 & 0.449 & $<0.001$ & 0.128 & 0.481 \\
\hline Total bilirubin, $\mu \mathrm{mol} / \mathrm{L}$ & 1.20 & 1.31 & 1.19 & 1.28 & 1.18 & 0.06 & 0.632 & 0.805 & 0.037 & 0.475 \\
\hline ALP, U/L & 125 & 112 & 121 & 127 & 112 & 4.6 & 0.521 & 0.032 & 0.503 & 0.023 \\
\hline TRAP, U/L & 5.76 & 6.51 & 5.96 & 6.52 & 5.64 & 0.26 & 0.425 & 0.892 & 0.888 & 0.066 \\
\hline $\mathrm{LDH}, \mathrm{U} / \mathrm{L}$ & $747^{b}$ & $769^{b}$ & $947^{\mathrm{a}}$ & 770 & 865 & $741-839$ & 0.005 & 0.071 & 0.822 & 0.114 \\
\hline
\end{tabular}

${ }^{1}$ BHBA, D-3-Hydroxybutyrate; ALT, alanine aminotransferase; AST, aspartate aminotransferase; ALP, alkaline phosphatase; GGT, $\gamma$-glutamyltransferase; LDH, L-lactate dehydrogenase; TRAP, tartrate-resistant acid-phosphatase; CAB, plasma cation-anion balance.

${ }^{2} \mathrm{CON}$, control diet with $0 \%$ WECS; $15 \mathrm{WECS}$, diet with $15 \%$ WECS on a DM basis; 30 WECS, diet with $30 \%$ WECS on a DM basis.

${ }^{3}$ The SEM is pooled and the CI applies to variables not normally distributed.

${ }^{\mathrm{a}, \mathrm{b}}$ Within a row, means without common superscripts $\operatorname{differ}(\mathrm{P}<0.05)$.

\section{Serum Protein Profile}

Serum protein fractions are reported in Table 4. All the variables were unaffected by diet and by time of sampling, but $\beta$-globulins were affected by housing in metabolic cages $(P=0.006)$, with lower values (percentage on total serum protein) than those of barrows reared in group pens.

\section{DISCUSSION}

There are few papers with which to compare our results about the relationships between dietary carbohydrate source and pig hematology (Nofrarías et al., 2007; Hong et al., 2012). Nofrarías et al. (2007) related the hematological profile of growing pigs to a different supply of raw potato starch (RPS) as a source of resistant starch, which is able to reach the large intestine to be fermented by bacteria. After $90 \mathrm{~d}$ of treatment, the authors observed a reduced amount of circulating WBC and NEU in pigs fed RPS, and they explained this as a consequence of an improved gut mucosal integrity and function in pigs fed RPS. In contrast, Hong et al. (2012) did not report any difference in hematological traits between pigs fed high or low fermentable carbohydrate content in the diet. There are no signs that lead us to suspect a different gut tissue integrity in barrows fed WECS. However, considering the different result in the NEU to LYM ratio, further research on this issue is necessary. Cappai et al. (2013) reported the involvement of blood leukocytes (mainly as LYM and NEU) in the local response to gastric mucosa 
Table 4. Effects of different dietary inclusion of whole ear corn silage (WECS) and the exit from a metabolic cage on serum protein profile in barrows; alues are reported as LSM

\begin{tabular}{|c|c|c|c|c|c|c|c|c|c|c|}
\hline \multirow[b]{2}{*}{ Item } & \multicolumn{3}{|c|}{$\operatorname{Diet}^{1}$} & \multicolumn{2}{|c|}{ Housing } & \multirow[b]{2}{*}{ SEM $^{2}$} & \multicolumn{4}{|c|}{$P$-value } \\
\hline & $\mathrm{CON}$ & 15WECS & 30WECS & Pen & Cage & & Diet (D) & Sampling (S) & $\mathrm{D} \times \mathrm{S}$ & Housing \\
\hline Albumin, \% & 48.9 & 47.9 & 48.4 & 48.1 & 48.7 & 0.54 & 0.733 & 0.330 & 0.014 & 0.341 \\
\hline$\alpha$-globulin, $\%$ & 19.4 & 20.2 & 19.4 & 19.5 & 19.8 & 0.38 & 0.583 & 0.484 & 0.083 & 0.517 \\
\hline$\beta$-globulin, $\%$ & 11.2 & 11.5 & 11.9 & 12.3 & 10.8 & 0.32 & 0.635 & 0.326 & 0.157 & 0.006 \\
\hline$\gamma$-globulin, $\%$ & 20.6 & 20.3 & 20.3 & 20.1 & 20.7 & 0.41 & 0.966 & 0.349 & 0.370 & 0.125 \\
\hline
\end{tabular}

${ }^{1} \mathrm{CON}$, control diet with $0 \%$ WECS; $15 \mathrm{WECS}$, diet with $15 \%$ WECS on a DM basis; $30 \mathrm{WECS}$, diet with $30 \%$ WECS on a DM basis.

${ }^{2}$ The SEM is pooled.

chronic lesion, which may be affected by diet particle size. Nevertheless, adopting a dietary treatment fully comparable with our experimental conditions, Mason et al. (2013) evidenced a reduced severity in gastritis in pigs fed WECS. This leads us to suppose that the small differences in NEU and NEU to LYM ratio in our trial were not related per se to a possible effect of WECS on mucosa integrity. Nofrarías et al. (2007) also observed an increase in peripheral Hgb concentration as a probable consequence of an increased butyrate-mediated induction on hematopoietic tissues. The lack of differences between groups in circulating $\mathrm{Hgb}$ concentration likely excludes a possible role of a different butyrate production in the gut as a consequence of the different WECS percentages in the diets (Nofrarías et al., 2007).

The lack of difference between group pen and metabolic cage-housed barrows for the leukocyte items demonstrated an absence of a chronic stress in the latter kind of pigs. The effect of a deprived environment (de Groot et al., 2000) or isolation (Schönreiter and Zanella, 2000) on cortisol secretion as a sign of chronic stress is well documented in farm animals including the pig. However, our results may be inconclusive; it is the first time, to our knowledge, that a trial on fattening barrows compares animals fed the same diet in barn pens or in metabolic cages. From the point of view of animal welfare, it seems that metabolic cages did not interfere per se with the metabolism through a different degree of chronic stress. The effect of metabolic cages on erythrocyte items was probably due to an effect of different hydration and blood volume. This may be argued if one considers the higher values related to the blood concentration (RBC, Hgb, HCT) but not for those related to erythrocyte quality (MCV, $\mathrm{MCH}, \mathrm{MCHC})$.

The site of carbohydrate digestion affects the metabolic profile of pigs (Bertram et al., 2006). Considering the substitution of dry corn meal for WECS, we must take into account a possible change in the digestion site of corn starch, which is due to the different hydration degree and particle size. The partial reduction in OM digestibility, when high-fiber levels are used in pig diets, is diminished in its extent in heavy pigs like those typi- cally raised for Italian heavy pig production (Galassi et al., 2004, 2005, 2010) and is consistent with the findings on the contribution of hindgut in fiber digestion at different body weights (Shi and Noblet, 1994).

The increase in plasma NEFA observed in groups fed WECS was mirrored in the ratio of NEFA to cholesterol and NEFA to albumin. This result confirmed the increased plasma NEFA in pigs associated with a higher absorption of short-chain fatty acids (SCFA) from the large intestine due to increased caecal fermentations. There are few data regarding this issue. The most recent are from Yde et al. (2011), who reported an increase in plasma NEFA of gestating sows as a result of the use of fibrous by-products to substitute for starch from cereals (barley and wheat), which is associated with an increased large intestine absorption of SCFA. There was an increase in plasma NEFA (Fig. 1) and a decrease in plasma glucose as age advanced. This agrees with the results from Galassi et al. $(2004,2010)$ and is explained by the increased ability to digest OM when high-fiber levels are used in diets for heavy pigs. Weber and Kerr (2012) reported increased plasma NEFA in pigs fed sugar beet pulp as a source of dietary fiber. They considered this effect to be the result of the increased expression of adipose triglyceride lipase in adipose tissue, and they linked this response to a different effect of dietary fiber source on lipid absorption, thus stimulating a repartitioning of body lipid stores. In our case, without differences in fiber intake or fiber digestibility between groups (Zanfi et al., 2014), a possible explanation relies on a different partition in nutrient digestion throughout the gut. This difference could be hypothesized from the different granularity of the diets due to the presence of WECS, which was characterized by a higher percentage of particles in the upper sieving fraction. The lack of linearity in the response when increased amount of WECS was fed may be attributed to an excessive $\mathrm{pH}$ decrease in $30 \mathrm{WECS}$. This could be partially confirmed by the decrease in fecal $\mathrm{pH}$ with a diet containing ear corn silage and with a higher animal weight (Zanfi et al., 2014).

To explain the differences between group pen and cage-reared pigs in plasma metabolites, we need the 
aid of the results from de Haer and de Vries (1993) who compared the DM digestibility for pigs housed individually vs. those grouped. Even if the individual housing is not a metabolic cage, the different digestibility coefficient (higher in individually housed pigs) accounts for a part of the differences recorded in our trial, and it is not related to a possible isolation stress using plasma glucose as an example.

Plasma glucose, NEFA, and the glucose to NEFA ratio were affected by the use of metabolic cages, and this must be considered for the interpretation of the plasma metabolic profile in cage trial. This is the first time, to our knowledge, that a comparison was allowed between pigs fed the same diet but housed in a group-pen (with freedom of movement) or in a metabolic cage (reduced metabolism). The higher plasma glucose in barrows reared in the metabolic cages compared with those fed in the group-pens may be attributed to the concomitance of a lower glucose clearance in the cage (which is the result of reduced movement and, therefore, lower skeletal muscle requirement) and of a higher OM digestibility, which is generally associated with higher plasma glucose levels in monogastric animals (Nafikov and Beitz, 2007).

In their experiment, Zervas and Zijlstra (2002) reported an effect of dietary fiber on preprandial plasma urea that was reduced 17 and 39\% and included soyhulls or sugar beet pulp, respectively, in the diets of growing pigs. They justified the result as an effect due to the inclusion of fermentable fiber in the diet. The protein and the AA that are not digested and absorbed in the small intestine generate ammonia in the large intestine, and this ammonia may be used by intestinal microflora (fermenting fiber) for protein synthesis or absorbed in the blood. This ammonia is transformed to urea in the liver and excreted as urea in urine (Mosenthin et al., 1992). From the other components of nitrogen metabolism in plasma (creatinine but also proteins), we can exclude an effect of WECS content of the whole nitrogen and protein metabolism in the barrow.

Another interesting trend is the decrease in $\mathrm{Fe}$ plasma concentration with the increased amount on WECS in the diet. This may be explained by considering the aforementioned lower phytase activity in WECS compared with that in wheat bran. We did not test Fe availability in the 3 diets; however, this seems to be the primary explanation. Shelton et al. (2004) suggested the importance of the action of microbial phytase; we have no reason to exclude a comparable action from the phytase activity present in the wheat bran. The different availability of Fe was not mirrored in the hematological profile because the time of the trial was too short to show an effect that requires a significant renewal of circulating erythrocytes (Withrow and Bell, 1969). This item was also affected by metabolic cage, which re- sulted in increased plasma Fe. However, as previously stated about the erythrocyte features, this is probably the effect of a different (reduced) hemodilution in barrows reared in metabolic cages.

The increased inclusion of WECS, reducing $\mathrm{P}$ intake and fecal $\mathrm{P}$ excretion but also reducing retained $\mathrm{P}$ (Zanfi et al., 2014), did not affect plasma inorganic $P$ as much as the plasma activities of ALP and TRAP, 2 enzymes generally affected by reduced $\mathrm{P}$ availability. As outlined by Gutzwiller et al. (2011), the P requirement to achieve the optimal bone mineralization in pigs is greater than that for the maximum growth rate; therefore, the good growth obtained in WECS groups (Zanfi et al., 2014) was not a reference per se for $P$ availability or animal welfare. Further, as reviewed by Arnett (2003), acidogenic diets may stimulate bone resorption, compromising bone mineralization, and this aspect must be taken into account in a study that changes the carbohydrate source in the diet. An important ratio to consider in growing swine is that between digestible $\mathrm{P}$ $(\mathrm{g})$ and $\mathrm{DE}(\mathrm{MJ})$. In our trial, the passage from the CON to the 30WECS diet reduced the ratio between $\mathrm{P}$ and energy intake $(0.27,0.20$, and $0.17 \mathrm{~g}$ of $\mathrm{P} / \mathrm{MJ}$ for $\mathrm{CON}$, 15WECS, and 30WECS, respectively).

The housing effect on plasma protein components, with higher values in barrows reared in metabolic cages compared with those in group pens, jointly with the results from $\mathrm{RBC}, \mathrm{Hgb}$, and HCT suggested a condition of hemoconcentration in the former, which is also argued in the paper by Houpt and Yang (1995). The lack of interference from hepatic functionality is evidenced by the lack of difference in hepatic and hepatobiliary markers (ALT, AST, GGT, and bilirubin) and in the albumin to globulin ratio.

Housing affected both plasma $\mathrm{Ca}$ and $\mathrm{P}$, but in an opposite sense, and thus different hemodilution may not be the explanation. The 2 enzymatic activities related to bone metabolism (ALP and TRAP) were reduced in the metabolic cage, suggesting a lower bone metabolism in this housing. Therefore, the different behavior of $\mathrm{Ca}$ and $\mathrm{P}$ may be attributable to the main source of their plasma pool. Probably, the higher plasma $\mathrm{Ca}$ is related to the increased plasma albumin concentration. At the same time, the lower plasma $\mathrm{P}$ of barrows in metabolic cages may be the result of a lower mobilization from the ready available bone pool.

The $\beta$-globulin fraction is known to be changed during inflammation, such as in acute-phase proteins. A plausible explanation for the reduced percentage of this fraction in serum of cage-housed barrows could be related to a lower inflammatory status in animals with reduced physical activity. However, the values are substantially consistent with the relatively few data available in the literature (Miller et al., 1961a; Odink et al., 1990). 
Summarizing our results, it was demonstrated how WECS can replace in 1 feed both a source of starch and a source of digestible fiber for growing-finishing heavy pigs. Data obtained in metabolic cages could be considered comparable with those obtained in group pens when experimental diets are compared and no interaction between the tested diets and the housing were reported, even if the absolute values of plasma metabolites can be affected by a relatively different hemodilution.

\section{LITERATURE CITED}

Arnett, T. 2003. Regulation of bone cell function by acid-base balance. Proc. Nutr. Soc. 62:511-520.

Bertram, H. C., K. E. Bach Knudsen, A. Serena, A. Malmendal, N. C. Nielsen, X. C. Fretté, and H. J. Andersen. 2006. NMRbased metabolomic studies reveal changes in the biochemical profile of plasma and urine from pigs fed high-fibre rye bread. Br. J. Nutr. 95:955-962.

Boone, L., D. Meyer, P. Cusick, D. Ennulat, A. Provencher Bolliger, N. Everds, V. Meador, G. Elliott, D. Honor, D. Bounous, and H. Jordan. 2005. Selection and interpretation of clinical pathology indicators of hepatic injury in preclinical studies. Vet. Clin. Pathol. 34:182-188.

Boyd, R. D., D. Hall, and J. F. Wu. 1983. Plasma alkaline phosphatase as a criterion for determining biological availability of phosphorus for swine. J. Anim. Sci. 57:396-401.

Bucholtz, H. 2012. Key points in harvesting and storing high moisture corn. In: Proc. Tri-State Dairy Nutr. Conf., Fort Wayne, IN. p. 119-125.

Cappai, M. G., M. Picciau, and W. Pinna. 2013. Ulcerogenic risk assessment of diets for pigs in relation to gastric lesion prevalence. BMC Vet. Res. 9:36.

de Groot, J., I. C. de Jong, I. T. Prelle, and J. M. Koolhaas. 2000. Immunity in barren and enriched housed pigs differing in baseline cortisol concentration. Physiol. Behav. 71:217-223.

de Haer, L. C. M., and A. G. de Vries. 1993. Feed intake patterns of and feed digestibility in growing pigs housed individually or in groups. Livest. Prod. Sci. 33:277-292.

Farver, T. B. 1997. Concepts of normality in clinical biochemistry. In: J. J. Kaneko, J. W. Harvey, and M. L. Bruss, editors, Clinical biochemistry of domestic animals. Academic Press, San Diego, CA. p. 1-19.

Galassi, G., S. Colombini, L. Malagutti, G. M. Crovetto, and L. Rapetti. 2010. Effects of high fibre and low protein diets on performance, digestibility, nitrogen excretion and ammonia emission in the heavy pig. Anim. Feed Sci. Technol. 134:326-336.

Galassi, G., G. M. Crovetto, and L. Malagutti. 2005. Effect of beet pulp on growing performance, digestibility, $\mathrm{N}$ balance, and ammonia emission in the heavy pig. Ital. J. Anim. Sci. 4:458-460.

Galassi, G., G. M. Crovetto, L. Rapetti, and A. Tamburini. 2004. Energy and nitrogen balance in heavy pigs fed different fibre sources. Livest. Prod. Sci. 85:253-262.

Gutzwiller, A., H. D. Hess, A. Adam, D. Guggisberg, A. Liesegang, and P. Stoll. 2011. Effects of a reduced calcium, phosphorus and protein intake and of benzoic acid on calcium and phosphorus metabolism of growing pigs. Anim. Feed Sci. Technol. 168:113-121.

Hong, S. M., J. H. Hwang, and I. H. Kim. 2012. Evaluation of the effect of low dietary fermentable carbohydrate content on growth performance, nutrient digestibility, blood characteristics, and meat quality in finishing pigs. Asian-Australas J. Anim. Sci. 25:1294-1299.

Houpt, T. R., and H. Yang. 1995. Water deprivation, plasma osmolality, blood volume, and thirst in young pigs. Physiol. Behav. 57:49-54.
Italian Ministry of Health. 1992. Protezione degli animali utilizzati a fini sperimentali o ad altri fini scientifici, D. lgs 116/92. Gazz. Ufficiale 40:5-25.

Klem, T. B., E. Bleken, H. Morberg, S. I. Thorensen, and T. Framstad. 2010. Hematologic and biochemical reference intervals for Norwegian crossbreed grower pigs. Vet. Clin. Pathol. 39:221-226.

Littell, R. C., P. R. Henry, and C. B. Ammerman. 1998. Statistical analysis of repeated measures data using SAS procedures. J. Anim. Sci. 76:1216-1231.

Mason, F., E. Pascotto, C. Zanfi, and M. Spanghero. 2013. Effect of dietary inclusion of whole ear corn silage on stomach development and gastric mucosa integrity of heavy pigs at slaughter. Vet. J. 198:717-719.

Miller, E. R., D. E. Ullrey, I. Ackerman, D. A. Schmidt, J. A. Hoefer, and L. W. Luecke. 1961a. Swine hematology from birth to maturity. I. Serum proteins. J. Anim. Sci. 20:31-35.

Miller, E. R., D. E. Ullrey, I. Ackerman, D. A. Schmidt, R. W. Luecke, and J. A. Hoefer. 1961b. Swine hematology from birth to maturity. II. Erythrocyte population, size and hemoglobin concentration. J. Anim. Sci. 20:890-897.

Mosenthin, R., W. C. Sauer, H. Henkel, F. Ahrens, and C. F. M. de Lange. 1992. Tracer studies of urea kinetics in growing pigs. II. The effect of starch infusion at the distal ileum on urea recycling and bacterial nitrogen excretion. J. Anim. Sci. 70:3467-3472.

Nafikov, R. A., and D. C. Beitz. 2007. Carbohydrate and lipid metabolism in farm animals. J. Nutr. 137:702-705.

Nofrarías, M., D. Martínez-Puig, J. Pujols, N. Majó, and J. F. Pérez. 2007. Long-term intake of resistant starch improves colonic mucosal integrity and reduces gut apoptosis and blood immune cells. Nutrition 23:861-870.

Odink, J., J. F. M. Smeets, I. J. R. Visser, H. Sandman, and J. M. A. Snijders. 1990. Hematological and clinicochemical profiles of healthy swine and swine with inflammatory processes. J. Anim. Sci. 68:163-170.

Schönreiter, S., and A. J. Zanella. 2000. Assessment of cortisol in swine by saliva: New methodological approaches. Arch. Tierz. 43:165-170.

Schrøder-Petersen, D. L., and H. B. Simonsen. 2001. Tail biting in pigs. Vet. J. 162:196-210.

Shelton, J. L., L. L. Southern, F. M. LeMieux, and T. D. Bidner. 2004. Effect of microbial phytase, low calcium and phosphorus, and removing the trace mineral premix on carcass traits, pork quality, plasma metabolites, and tissue mineral content in growing-finishing pigs. J. Anim. Sci. 82:2630-2639.

Shi, X. S., and J. Noblet. 1994. Effect of body weight and feed composition on the contribution of hindgut to digestion of energy and nutrients in pigs. Livest. Prod. Sci. 38:225-235.

Weber, T. E., and B. J. Kerr. 2012. Metabolic effects of dietary sugar beet pulp or wheat bran in growing female pigs. J. Anim. Sci. 90:523-532.

Withrow, G., and M. C. Bell. 1969. Erythrocytic life span estimations in growing sheep and swine using ${ }^{75} \mathrm{Se}$. J. Anim. Sci. 28:240-245.

Yde, C. C., H. C. Bertram, P. K. Theil, and K. E. Bach Knudsen. 2011. Effects of high dietary fibre diets formulated from byproducts from vegetable and agricultural industries on plasma metabolites in gestating sows. Arch. Anim. Nutr. 65:460-476.

Zanfi, C., S. Colombini, F. Mason, G. Galassi, L. Rapetti, L. Malagutti, G. M. Crovetto, and M. Spanghero. 2014. Digestibility and metabolic utilization of diets containing whole-ear corn silage and their effects on growth and slaughter traits of heavy pigs. J. Anim. Sci. 92:211-219.

Zervas, S., and R. T. Zijlstra. 2002. Effects of dietary protein and fermentable fiber on nitrogen excretion patterns and plasma urea in grower pigs. J. Anim. Sci. 80:3247-3256. 